\title{
Therapeutic drug monitoring of posaconazole for effective prophylaxis of invasive fungal infections in pediatric patients: a pilot study
}

\author{
Karolina Liszka ${ }^{\# * 1}$ (D), Matylda Resztak² ${ }^{\# 2}$ Paulina Zalewska ${ }^{2}$, Krzysztof Kałwak $^{1}$ \\ ${ }^{1}$ Department of Pediatric Bone Marrow Transplantation, Oncology, and Hematology, Wroclaw Medical University, Wroclaw, Poland
}

${ }^{2}$ MonitLab Sp. z o.o., Poznan, Poland

${ }^{\#}$ Authors contributed equally to work

\begin{abstract}
Introduction: Posaconazole, a second-generation triazole agent, is a drug with wide interindividual variation in bioavailability and variability of pharmacokinetics. The European Conference on Infections in Leukemia recommends the implementation of posaconazole therapeutic drug monitoring (TDM) in children to provide certainty regarding the efficacy of treatment and to increase its safety. A concentration of posaconazole in plasma in prophylactic regimens of above $0.7 \mathrm{mg} / \mathrm{L}$ is recommended.
\end{abstract}

The aim of our pilot study was to discover the most effective method of posaconazole plasma concentration measurement, and to analyze posaconazole pharmacokinetics profiles in pediatric patients on posaconazole prophylaxis.

Material and methods: Children receiving oncological treatment or hematopoietic stem cell transplantation in the Department of Pediatric Bone Marrow Transplantation, Oncology, and Hematology in Wroclaw Medical University Hospital were included in the trial. Posaconazole concentration was determined at the MonitLab ${ }^{\mathrm{TM}}$ laboratory using a newly validated high-performance liquid chromatography with fluorescence detector method.

Results: Initial analysis shows that the major problem in patients on antifungal prophylaxis is inadequately low plasma drug concentration.

Conclusions: Clinical trials on TDM of posaconazole should be developed.

Key words: posaconazole, therapeutic drug monitoring (TDM), antifungal prophylaxis

Acta Haematologica Polonica 2021; 52, 6: 578-583

\section{Introduction}

The appropriate medication dosage often depends on a patient's individual metabolism patterns, and therefore closer cooperation between physicians and pharmacologists seems sensible. One solution that enables therapy to be customized to the individual patient's needs is therapeutic drug monitoring (TDM).
TDM provides certainty as to the efficacy of treatment by confirming that the plasma concentration of medicine is fixed within the desired level. It increases the safety and efficacy of the implementation of the drugs within a narrow therapeutic range (NTR).

Posaconazole is a second-generation triazole agent with a broad spectrum of activity against a range of important fungal pathogens including: Aspergillus spp.,

\footnotetext{
*Address for correspondence: Karolina Liszka, Department of Pediatric Bone Marrow Transplantation, Oncology, and Hematology, Wroclaw Medical University, Borowska 213, 50-556 Wroclaw, Poland; e-mail: cuccinna@gmail.coml
}

PTHiT Copyright $\odot 2021$

The Polish Society of Haematologists and Transfusiologists, Insitute of Haematology and Transfusion Medicine. All rights reserved. 
Candida spp., Mucormycetes spp., and Fusarium spp. As a result, it is widely used in pediatric onco-hematological wards, because fungal infections are one of the most frequent complications that occur in immunocompromised patients. Appropriate prophylaxis and targeted treatment decrease mortality rates significantly. However, it should be remembered that the therapeutic efficacy of posaconazole is conditional upon achieving a plasma drug concentration target at a steady state, which should be considered as an equivalent to the minimum inhibitory concentration $\left(\mathrm{MIC}_{90}\right)$ for a pathogen causing an infection.

Posaconazole is a drug with wide interindividual variation in bioavailability and well-recognized variability of pharmacokinetics. For that reason, the European Conference on Infections in Leukemia (ECIL) recommends the implementation of posaconazole TDM in children as routine practice to ensure an adequate exposure, and to optimize the clinical response [1].

Medicines involved in drug-to-drug interactions (DDIs) can be divided into two groups: victims - i.e. drugs that are directly affected by DDIs, and perpetrators - i.e. drugs that cause DDIs. Posaconazole can act in both ways. It can be affected as a victim drug by interactions with medicines that interact with uridine 5'-diphospho-glucuronosyltransferase (UGT) enzymes or P-glycoprotein. Nearly $20 \%$ of posaconazole is glucuronidated by UGT1A4. Both inducers (e.g. rifampicin, some anticonvulsants) and inhibitors of the enzyme (e.g. verapamil, cyclosporin A, macrolides) can alter posaconazole's plasma concentration.

On the other hand, posaconazole is also an inhibitor of CYP3A4, so it affects the metabolism of drugs that are substrates for that enzyme, such as cyclosporin A [2].

Although posaconazole is characterized by better tolerance and fewer interactions than other azoles, its pharmacokinetics is affected also by other factors such as: the clinical condition of the patient, the patient's age, the route of drug administration, and the means of the patient's feeding, all of which can be associated with altered medicine absorption. It is recommended to ingest this medication with a meal that is rich in lipids, or with soda drinks that increase the acidity. Proton pump inhibitors, as well as metoclopramide or gastrointestinal tract disorders such as mucositis or diarrhea, are known to decrease the bioavailability of posaconazole [2]. Because of this, these patients require especially precise dose adjustments according to posaconazole's plasma concentration in order to provide effective antifungal treatment or prophylaxis.

In Poland, two posaconazole formulations are available: - suspension (this has possible bioavailability issues, is reimbursed for antimold prophylaxis in patients who underwent hematopoietic stem cell transplantation (HSCT) and who receive high dose immunosuppressive drugs due to graft-versus-host disease (GvHD) - children with myelodysplastic syndrome (MDS) prepared for HSCT, secondary antifungal prophylaxis after HSCT, chronic granulomatous disease with frequent fungal organ infections, children with acute myeloblastic leukemia (AML), myelodysplastic syndrome, acute lymphoblastic leukemia (ALL), recurrence of ALL or AML, malignant lymphomas or solid tumors receiving chemotherapy that can lead to prolonged neutropenia with high risk of fungal infections, and secondary antimold prophylaxis until chemotherapy or immunosuppressive therapy is completed; - intravenous formulation (this is expensive, and is used in rare cases of patients who are unable to take the suspension).

Until now, slow-release tablets have not been available in Poland, although they offer much better bioavailability and stability [2].

According to ECIL-8 recommendations, the suggested concentration of posaconazole in plasma in prophylactic regimens is a concentration of above $0.7 \mathrm{mg} / \mathrm{L}$ [1]. It has been demonstrated that a concentration above $3 \mathrm{mg} / \mathrm{L}$ can be associated with the occurrence of side effects. If we derive our data from voriconazole, then a concentration of above $6 \mathrm{mg} / \mathrm{L}$ would be considered as associated with toxicity (predominantly neurotoxicity) [3].

TDM in clinical practice is based on measuring plasma drug concentration at designated intervals, when the steady state in patients' blood is obtained. For posaconazole, this is reached after 7-10 days of therapy. The main purpose of the implementation of posaconazole TDM in everyday practice is to improve the safety of posaconazole therapy in a way that will enable us to achieve the optimal medical outcome and limit side effects. To implement TDM of posaconazole in standard routine practice, we need a method of serum concentration assessment that is simple, quick, and cost effective.

The aim of our pilot study was to find the most effective method of posaconazole pharmacokinetics (PK) measurement, and to analyze PK profiles in pediatric patients on posaconazole prophylaxis.

\section{Material and methods}

Our subjects were selected from patients treated in the Department of Pediatric Bone Marrow Transplantation, Oncology, and Hematology at Wroclaw Medical University, Wroclaw, Poland. The protocol for this study was approved by the Wroclaw Medical University Ethics Committee before the study began. All the patients were administered posaconazole according to the Welzen's et al. [4] dosing recommendations. In the first phase of our clinical trial, we assessed a group of patients on posaconazole prophylaxis. We measured plasma drug concentration and we tried to review the impact of additional factors on posaconazole pharmacokinetics, factors that when compared to clinical data could help us to reach conclusions as to adequate and safe dosage modification in the future. 
Table I. Clinical trial results

\begin{tabular}{|c|c|c|c|c|c|c|c|c|c|c|c|}
\hline No. & Diagnosis & $\begin{array}{l}\text { Age in } \\
\text { years }\end{array}$ & $\begin{array}{l}\text { Weight } \\
\text { in kg }\end{array}$ & $\begin{array}{l}\text { Treatment } \\
\text { stage }\end{array}$ & $\begin{array}{l}\text { Day } \\
\text { on } \\
\text { POSA }\end{array}$ & $\mathrm{COH}$ & C $3 \mathrm{H}$ & C $5 \mathrm{H}$ & $\mathrm{C} 8 \mathrm{H}$ & $\begin{array}{l}\text { Median. } \\
\text { Con. }\end{array}$ & $\begin{array}{l}\text { Drugs with possible in- } \\
\text { teraction with POSA }\end{array}$ \\
\hline 1 & $\begin{array}{l}\text { CD40 } \\
\text { ligand } \\
\text { def. }\end{array}$ & 2 & 11 & $\begin{array}{l}\text { Day }+14 \text { af- } \\
\text { ter allo-HSCT }\end{array}$ & 25 & 0.74 & 1.02 & 1.05 & 1.21 & 1.04 & $\begin{array}{l}\text { Acyclovir, colistin, me- } \\
\text { ropenem, teicoplanin, } \\
\text { cyclosporin }\end{array}$ \\
\hline 2 & ALL & 4 & 14.6 & $\begin{array}{l}\text { Day }+49 \text { af- } \\
\text { ter allo-HSCT }\end{array}$ & 60 & 0.87 & 1.18 & 0.92 & 0.63 & 0.90 & $\begin{array}{l}\text { Sulfamethoxazole/ } \\
\text { /trimethoprim, } \\
\text { ursodeoxycholic acid }\end{array}$ \\
\hline 3 & ALL & 7 & 30.5 & $\begin{array}{l}\text { Day } 6 \text { HC1 } \\
\text { IntReALL } \\
2010\end{array}$ & 10 & 0.67 & 0.72 & 0.66 & 0.56 & 0.67 & $\begin{array}{l}\text { Sulfamethoxazole/ } \\
\text { trimethoprim, acyclovir, } \\
\text { ciprofloxacin, omepra- } \\
\text { zole }\end{array}$ \\
\hline 4 & AML & 3 & 11.5 & $\begin{array}{l}\text { Day - } 8 \text { befo- } \\
\text { re allo-HSCT }\end{array}$ & 90 & 0.44 & 0.63 & 0.56 & 0.50 & 0.53 & $\begin{array}{l}\text { Acyclovir, meropenem, } \\
\text { oxybutynin }\end{array}$ \\
\hline 5 & ALL & 10 & 30 & $\begin{array}{l}\text { Year after } \\
\text { allo-HSCT, } \\
\text { GvHD }\end{array}$ & 90 & 2.46 & 2.77 & 2.71 & 2.39 & 2.59 & $\begin{array}{l}\text { Sulfamethoxazole/ } \\
\text { /trimethoprim, } \\
\text { acyclovir, omeprazole, } \\
\text { mycofenolate mofetil, } \\
\text { methyloprednisolone, } \\
\text { levothyroxine, ursodeo- } \\
\text { xycholic acid }\end{array}$ \\
\hline 6 & ALL & 16 & 61 & $\begin{array}{l}\text { Day }+33 \text { af- } \\
\text { ter allo-HSCT, } \\
\text { GvHD }\end{array}$ & 8 & 0.26 & 0.32 & 0.30 & 0.33 & 0.31 & $\begin{array}{l}\text { Acyclovir, omeprazole, } \\
\text { methyloprednisolone, } \\
\text { cyclosporin, teicopla- } \\
\text { nin, ursodeoxycholic } \\
\text { acid }\end{array}$ \\
\hline 7 & $\begin{array}{l}\text { Lympho- } \\
\text { ma }\end{array}$ & 16 & 55.5 & $\begin{array}{l}\text { Day }+27 \text { af- } \\
\text { ter allo-HSCT }\end{array}$ & 8 & 1.42 & 1.02 & 1.56 & 1.23 & 1.33 & $\begin{array}{l}\text { Acyclovir, cyclosporin, } \\
\text { rifaximin, ursodeoxy- } \\
\text { cholic acid }\end{array}$ \\
\hline 8 & WAS & 5 & 18 & $\begin{array}{l}\text { Day }+50 \text { af- } \\
\text { ter allo-HSCT, } \\
\text { GvHD }\end{array}$ & 18 & 0.96 & 1.06 & 1.02 & 0.77 & 0.99 & $\begin{array}{l}\text { Amlodipine, atenolol, } \\
\text { mycophenolate mofetil, } \\
\text { colistin, cyclosporin, } \\
\text { etanercept, foscarnet } \\
\text { sodium, methylopred- } \\
\text { nisolone, letermovir, } \\
\text { rifaximin }\end{array}$ \\
\hline 9 & $\begin{array}{l}\text { Lympho- } \\
\text { ma }\end{array}$ & 16 & 59 & $\begin{array}{l}\text { Day }+3 \text { after } \\
\text { allo-HSCT }\end{array}$ & 15 & 0.37 & 0.45 & 0.39 & 0.27 & 0.38 & $\begin{array}{l}\text { Sulfamethoxazole/tri- } \\
\text { methoprim, hydrocorti- } \\
\text { sone, colistin, acyclovir, } \\
\text { ursodeoxycholic acid, } \\
\text { cyclosporin }\end{array}$ \\
\hline 10 & ALL & 11 & 33 & $\begin{array}{l}\text { Day }+10 \text { af- } \\
\text { ter CAR-T }\end{array}$ & 400 & 0.69 & 0.86 & 0.84 & 0.76 & 0.80 & $\begin{array}{l}\text { Sulfamethoxazole/ } \\
\text { /trimethoprim, ciproflo- } \\
\text { xacin, acyclovir, leveti- } \\
\text { racetam, tocilizumab }\end{array}$ \\
\hline 11 & ALL & 6 & 30 & $\begin{array}{l}17 \text { days after } \\
\text { Protocol II } \\
\text { AlEOP-BFM } \\
\text { ALL } 2017\end{array}$ & 7 & 3.06 & 3.65 & 2.93 & 2.75 & 3.00 & $\begin{array}{l}\text { Sulfamethoxazole/tri- } \\
\text { methoprim, nystatin }\end{array}$ \\
\hline 12 & AML & 4 & 18 & $\begin{array}{l}\text { Day }+18 \text { af- } \\
\text { ter HSCT }\end{array}$ & 28 & 0.7 & 0.62 & 0.63 & 0.55 & 0.63 & $\begin{array}{l}\text { Sulfamethoxazole/ } \\
\text { /trimethoprim, cipro- } \\
\text { floxacin, acyclovir, } \\
\text { cefepime, cyclosporin, } \\
\text { teicoplanin, ursodeoxy- } \\
\text { cholic acid }\end{array}$ \\
\hline
\end{tabular}


Table I (cont.). Clinical trial results

\begin{tabular}{|l|l|l|l|l|l|l|l|l|l|l|}
\hline No. & Diagnosis & $\begin{array}{l}\text { Age in } \\
\text { years }\end{array}$ & $\begin{array}{l}\text { Weight } \\
\text { in } \mathbf{k g}\end{array}$ & $\begin{array}{l}\text { Treatment } \\
\text { stage }\end{array}$ & $\begin{array}{l}\text { Day } \\
\text { on } \\
\text { POSA }\end{array}$ & $\mathbf{C ~ O H}$ & $\mathbf{C ~ 3 H}$ & $\mathbf{C ~ 5 H}$ & $\mathbf{C ~ 8 H}$ & $\begin{array}{l}\text { Median. } \\
\text { Con. }\end{array}$ \\
\hline
\end{tabular}

Drugs in bold are those known to take part in drug-to-drug interactions with posaconazole (POSA) suspension, leading to decreases in its bioavailbility and serum concentration. Drugs in italics are those known to take part in drug-to-drug interactions with posaconazole suspension, leading to an increase in its serum concentration; $\mathrm{C} \mathrm{OH}, \mathrm{C} 3 \mathrm{H}, \mathrm{C} 5 \mathrm{H}, \mathrm{C} 8 \mathrm{H}-$ time points of taking samples from the patients, $\mathrm{COH}$ - just before the drug administration and then 3, 5, 8 hours after; allo-HSCT - allogeneic hematopoietic stem cell transplantation; ALL - acute lymphoblastic leukemia; GvHD - graft-versus-host disease; AML - acute myeloblastic leukemia; CAR-T - chimeric antigen receptor T cells; WAS - Wiskott-Aldrich syndrome; Ara-C - cytosine arabinoside

Blood samples were obtained from 15 patients during their hospitalization. The samples were taken after seven days of treatment with posaconazole, after reaching the drug steady state at four time points: 0 - just before the drug administration, and then three, five and eight hours after. The sample volume needed for analysis was $0.5 \mathrm{~mL}$. All blood samples were centrifuged $\left(3,500 \mathrm{~g}\right.$ at $20^{\circ} \mathrm{C}$ for $5 \mathrm{~min}$ ) and plasma was stored at $-20^{\circ} \mathrm{C}$ until analysis. For each plasma sample, posaconazole concentration was determined at the MonitLab ${ }^{\mathrm{TM}}$ laboratory in Poznan, Poland using a newly validated high-performance liquid chromatography with fluorescence detector (HPLC-FLD) method. Chromatographic separation was achieved with the mobile phase consisting of acetonitrile/water with a flow rate of $1.3 \mathrm{~mL} / \mathrm{min}$. Each sample injection volume was $2 \mu \mathrm{L}$. $50 \mu \mathrm{L}$ of patient plasma was used for the analysis. Protein precipitation procedure was applied for the extraction of posaconazole from plasma samples. The validation of the analytical method was carried out according to the guidelines on bioanalytical method validation of the European Medicines Agency (EMA).

\section{Results}

\section{Demographics and TDM}

The ages of our preliminary group of patients ranged from one to 16 years. 10 out of 15 patients included in the trial were diagnosed with leukemia, two patients suffered from lymphoma, and three had immunodeficiency syndromes such as CD40 ligand deficiency and Wiskott-Aldrich syndrome (WAS). 6/15 patients (40\%) included in the trial presented with the desired plasma concentration of posaconazole in the intervals between doses. $\ln 7 / 15$ patients (47\%), the plasma concentrations of posaconazole were lower, and were considered to be insufficient. All of these patients remained in the HSCT procedure, either before
( $n=2)$ or after HSCT ( $n=5)$. Two out of three patients who received parallel omeprazole had low posaconazole plasma concentrations.

In two patients (13\%), plasma posaconazole concentration reached an alarming level, bordering toxicity. Both these patients showed no known toxicity symptoms. Both were patients with ALL. The first patient was after the II protocol and the second one was during the Ib protocol (AIEOP-BFM ALL 2017) (Table I). This led us to hypothesize that the reason for the elevated plasma concentration of posaconazole was related to metabolic drug interaction.

\section{Interactions and side effects}

Our initial study results revealed that insufficient plasma drug concentration is the major problem in patients on antifungal prophylaxis. Inadequately low concentrations appear more frequently than do toxic levels. We cannot assess the correlation between the length of prophylaxis implementation in a patient and the low serum concentration of posaconazole so far. The problem affects both children on long-term treatment as well as patients who have just started oral antifungal prophylaxis. On the other hand, alarmingly high plasma serum concentrations of the drug occurred among patients who had just started their prophylactic regimen - both of the patients were tested on day 7 following the start of their oral posaconazole prophylactic regimen. Nevertheless, posaconazole treatment-related severe toxicity, such as hepatotoxicity or cardiotoxicity, occurs very rarely, i.e. $<1 \%$ [2]. Frequent adverse effects include gastrointestinal disorders, hypokalemia and pyrexia.

\section{Discussion}

The main purpose of the implementation of posaconazole TDM into everyday practice is to improve the safety and 
efficacy of posaconazole therapy in pediatric patients in a way that will enable the achievement of optimal prophylaxis efficacy and minimize any possible side effects.

To perform TDM of posaconazole in clinical practice, accurate, validated analytical methods have to be available. Up to now, a dozen methods for the estimation of posaconazole in biological samples have been published. High-performance liquid chromatography with UV [5-8] or FLD [9-11] detection and liquid chromatography-tandem mass spectrometry [12-16] remain the most advantageous in terms of therapeutic monitoring of drugs, because they enable reliable results to be obtained in a relatively short time.

Liquid chromatography with mass spectrometry and tandem mass spectrometry are preferable in sensitivity and specificity to ultraviolet or fluorescence detections. However, such instruments are expensive to purchase and are not affordable in many laboratories. The assay costs often exceed those of the other techniques, which are based on fluorescence (FLD) or ultraviolet (UV) detection. An elaborated procedure involving FLD detection is likely to be a more suitable alternative to routine TDM measurements of posaconazole.

Another point to consider is the sample pretreatment procedure. It is very important to simplify the analytical procedure so that it can be successfully used in therapeutic drug monitoring. Previously published HPLC-UV and FLD methods of posaconazole level measurement still use liquid-liquid extraction (LLE) $[6-8,11]$ or solid-phase extraction (SPE) [17] to separate the drug from the biological matrix. This is expensive and time-consuming.

Our method is much faster and more easily performed. It is based on one step plasma protein precipitation which reduces the potential errors resulting from changes in extraction efficiency. An extremely important facet of TDM practice is the aliquot of the matrix that is required for analysis, especially in pediatric patients. When compared to previously published HPLC-UV [6-8] or HPLC-FLD [9-11] methods in which the sample volume ranges from 100 to $500 \mu \mathrm{L}$, the current method allows the determination of posaconazole in plasma with a smaller serum sample $(50 \mu \mathrm{L})$ and a smaller injection volume $(2 \mu \mathrm{L})$. Finally, the total chromatographic run time of the method used is less than $7 \mathrm{~min}$, which is very important in TDM practice when results must be obtained as quickly as possible.

There are some limitations to our study. This was a single-center retrospective study with a small number of patients. The correlation between dosage, the plasma concentration of the drug, and the outcome of treatment was not assessed. No dose adjustment or repeat TDM measurements were performed.

We still have insufficient knowledge on which to build final conclusions, but undoubtedly clinical trials on TDM of posaconazole should be developed. It seems to be especially useful and important to secure reasonable treatment with drugs of unpredictable pharmacokinetics such as posaconazole. Despite the implementation of the drug according to the international dosage recommendations, we failed to obtain the desired plasma concentration in a significant proportion of children.

One possible conclusion after our trial could be that we are unable to assess which factors really influence posaconazole serum concentration. Hence, we will not be able to avoid or modify them. Due to that, therapeutic drug monitoring applied in routine practice should be implemented in Poland.

ECIL-4 and ECIL-8, the Polish Society of Pediatric Oncology and Hematology guidelines on antifungal prophylaxis, clearly recommend the use of TDM in children below a weight of $40 \mathrm{~kg}[1,18,19]$.

We will aim to assess an extended group of patients with the future roll-out of our research.

\section{Authors' contributions}

$\mathrm{KL}, \mathrm{MR}, \mathrm{PZ}, \mathrm{KK}$ - study design, MR, PZ - development of a method of posaconazole plasma concentration measurement, KL, KK - pharmacokinetic profiles and other data analysis, KL, MR, PZ, KK - manuscript preparation.

\section{Conflict of interest}

None.

\section{Financial support}

The sources of financial support for our research and publication were The National Center for Research and Development's BRIdge Alfa and Polish Venture Fund, as well as Wroclaw Medical University grant no B/01/ /11/2020.

\section{Ethics}

The work described in this article has been carried out in accordance with The Code of Ethics of the World Medical Association (Declaration of Helsinki) for experiments involving humans; EU Directive 2010/63/EU for animal experiments; Uniform requirements for manuscripts submitted to biomedical journals.

\section{References}

1. Groll AH, Pana D, Lanternier F, et al. 8th European Conference on Infections in Leukaemia. 8th European Conference on Infections in Leukaemia: 2020 guidelines for the diagnosis, prevention, and treatment of invasive fungal diseases in paediatric patients with cancer or post-haematopoietic cell transplantation. Lancet Oncol. 2021; 22(6): e254-e269, doi: 10.1016/S1470-2045(20)30723-3, indexed in Pubmed: 33811813.

2. Chen Lu, Krekels EHJ, Verweij PE, et al. Pharmacokinetics and pharmacodynamics of posaconazole. Drugs. 2020; 80(7): 671-695, doi: 10.1007/s40265-020-01306-y, indexed in Pubmed: 32323222. 
3. Dzierżanowska-Fangrat K, Gil L, Jakubas B, et al. Recommendations for therapy of invasive fungal disease in patients with hematological malignancy or undergoing hematopoietic stem cell transplantation. Post Nauk Med. 2015; 28(6): 411-418.

4. Welzen MEB, Brüggemann RJM, Van Den Berg JM, et al. A twice daily posaconazole dosing algorithm for children with chronic granulomatous disease. Pediatr Infect Dis J. 2011; 30(9): 794-797, doi: 10.1097/INF.0b013e3182195808, indexed in Pubmed: 21772229.

5. Cendejas-Bueno E, Forastiero A, Rodriguez-Tudela JL, et al. HPLC/ /UV or bioassay: two valid methods for posaconazole quantification in human serum samples. Clin Microbiol Infect. 2012; 18(12): 1229-1235, doi: 10.1111/j.1469-0691.2011.03732.x, indexed in Pubmed: 22192527.

6. Wissen CP, Burger DM, Verweij PE, et al. Simultaneous determination of the azoles voriconazole, posaconazole, isavuconazole, itraconazole and its metabolite hydroxy-itraconazole in human plasma by reversed phase ultra-performance liquid chromatography with ultraviolet detection. J Chromatogr B Analyt Technol Biomed Life Sci. 2012; 887-888: 79-84, doi: 10.1016/j.jchromb.2012.01.015, indexed in Pubmed: 22336695.

7. Chhun S, Rey E, Tran A, et al. Simultaneous quantification of voriconazole and posaconazole in human plasma by high-performance liquid chromatography with ultra-violet detection. J Chromatogr B Analyt Technol Biomed Life Sci. 2007; 852(1-2): 223-228, doi: 10.1016/j.jchromb.2007.01.021, indexed in Pubmed: 17306633.

8. Kahle K, Langmann P, Schirmer D, et al. Simultaneous determination of voriconazole and posaconazole concentrations in human plasma by high-performance liquid chromatography. Antimicrob Agents Chemother. 2009; 53(7): 3140-3142, doi: 10.1128/AAC.00213-09, indexed in Pubmed: 19380591.

9. Tang P. Determination of posaconazole in plasma/serum by high-performance liquid chromatography with fluorescence detection. Separations. 2017 ; 4(2): 16, doi: 10.3390/separations4020016.

10. Müller C, Arndt M, Queckenberg C, et al. HPLC analysis of the antifungal agent posaconazole in patients with haematological diseases. Mycoses. 2006; 49 Suppl 1: 17-22, doi: 10.1111/j.14390507.2006.01297.x, indexed in Pubmed: 16961577.

11. Buckner SL, Ceesay MM, Pagliuca A, et al. Measurement of posaconazole, itraconazole, and hydroxyitraconazole in plasma/serum by high-performance liquid chromatography with fluorescence detection. Ther Drug Monit. 2011; 33(6): 735-741, doi: 10.1097/ FTD.0b013e3182381bb1, indexed in Pubmed: 22105591.

12. Alffenaar JWC, Wessels AMA, van Hateren K, et al. Method for therapeutic drug monitoring of azole antifungal drugs in human serum using LC/MS/MS. J Chromatogr B Analyt Technol Biomed Life Sci.
2010; 878(1): 39-44, doi: 10.1016/j.jchromb.2009.11.017, indexed in Pubmed: 19945360.

13. Jenkins N, Black M, Schneider HG. Simultaneous determination of voriconazole, posaconazole, itraconazole and hydroxy-itraconazole in human plasma using LCMS/MS. Clin Biochem. 2018; 53: 110 -115, doi: 10.1016/j.clinbiochem.2018.01.004, indexed in Pubmed: 29325818.

14. Chae $\mathrm{H}$, Cho SY, Yu H, et al. Determination of posaconazole concentration with LC-MS/MS in adult patients with hematologic malignancy. Clin Chim Acta. 2015; 450: 220-226, doi: 10.1016/j. cca.2015.08.023, indexed in Pubmed: 26319883.

15. Vogeser $\mathrm{M}$, Rieger $\mathrm{C}$, Ostermann $\mathrm{H}$, et al. A routine method for the quantification of the novel antimycotic drug posaconazole in plasma using liquid chromatography-tandem mass spectrometry. Clin Chem Lab Med. 2009; 47(5): 579-584, doi: 10.1515/CCLM.2009.129, indexed in Pubmed: 19302035.

16. Rochat B, Pascual A, Pesse B, et al. Ultra-performance liquid chromatography mass spectrometry and sensitive bioassay methods for quantification of posaconazole plasma concentrations after oral dosing. Antimicrob Agents Chemother. 2010; 54(12): 5074-5081, doi: 10.1128/AAC.00022-10, indexed in Pubmed: 20921320.

17. Störzinger D, Swoboda S, Lichtenstern C, et al. Development and validation of a high-performance liquid chromatography assay for posaconazole utilizing solid-phase extraction. Clin Chem Lab Med. 2008; 46(12): 1747-1751, doi: 10.1515/CCLM.2008.338, indexed in Pubmed: 18973464.

18. Groll AH, Castagnola E, Cesaro S, et al. Fourth European Conference on Infections in Leukaemia, Infectious Diseases Working Party of the European Group for Blood Marrow Transplantation (EBMT-IDWP), Infectious Diseases Group of the European Organisation for Research and Treatment of Cancer (EORTC-IDG), International Immunocompromised Host Society (ICHS), European Leukaemia Net (ELN). Fourth European Conference on Infections in Leukaemia (ECIL-4): guidelines for diagnosis, prevention, and treatment of invasive fungal diseases in paediatric patients with cancer or allogeneic haemopoietic stem-cell transplantation. Lancet Oncol. 2014; 15(8): e327-e340, doi: 10.1016/S1470-2045(14)70017-8, indexed in Pubmed: 24988936.

19. Gil L, Kałwak K, Piekarska A, et al. Antifungal management in adults and children with hematological malignancies or undergoing hematopoietic cell transplantation: recommendations of Polish Society of Hematology and Blood Transfusion, Polish Society of Pediatric Oncology and Hematology, and Polish Adult Leukemia Study Group, 2020. Acta Haematol Pol. 2020; 51(2): 60-72, doi: 10.2478/ahp-2020-0014. 